\title{
Esg or Not Esg? A Benchmarking Analysis
}

\author{
Valeria Vannoni ${ }^{1} \&$ Emanuele Ciotti ${ }^{2}$ \\ ${ }^{1}$ University of Perugia, Department of Economics, Perugia, Italy \\ ${ }^{2}$ Fideuram Bank, Perugia, Italy \\ Correspondence: Valeria Vannoni, University of Perugia, Department of Economics, Italy. E-mail: \\ valeria.vannoni@unipg.it
}

Received: May 7, 2020

doi:10.5539/ijbm.v15n8p152

\begin{abstract}
Sustainable investments are increasingly leaving their niche position to enter financial markets in a remarkable way in recent years. In this scenario, ESG (Enviromental, Social, Governance) practices are emerging alongside the risk-return approaches that for years have exclusively determined the portfolio choices of investors.

This paper aims to give a contribution to the flourishing debate on the application of ESG criteria to investments' selection, using a case study through a benchmarking approach. The empirical investigation focuses on a two-level analysis of GIS Global Bond ESG Fund (EUR Hedged), managed by PIMCO management company. Results highlight that ESG practises should be referred more as a complementary rather than alternative approach for portfolio management.
\end{abstract}

Keywords: esg, sustainable investment, impact investing

JEL codes: G11, Q01.

\section{Introduction}

The demand for investments that combine financial return with desired social or environmental impact is growing: redirecting investment and finance to impact oriented investments compatible with the UN Sustainable Development Goals and the Paris Agreement is a key factor in turning around the investment philosophy. The concept of sustainable investment has spread since the 1960s, but still lacks a clear definition: the Global Sustainable Investment Alliance (GSIA) considers it as an investment approach that includes the ESG (Environmental, Social and Governance) facts in the selection and management of the portfolio (Tyler, 2018). Moreover, sustainable investment and ESG criteria are inevitably connected topics. The interest in the search for a virtuous relationship between the real and financial economy has returned to assert itself following the latest financial crisis, that has imposed, on a global level, a rethinking on the role of the financial system in support of the real economy and on the way in which to interpret the same role. The ethical profile of the investments and the responsible behavior of the investors represent an important way for bringing economy and finance closer together, allowing to draw attention to the social dimension of the phenomena. In this context, a new form of finance is emerging, as a sustainable investment strategy, the so-called impact investing. Although the sustainable investment market has traditionally been driven by institutional investors, there is growing interest in this sector also from private investors.

Our study focuses on the analysis of the GIS Global Bond ESG Fund (EUR Hedged) managed by PIMCO (Pacific Investment Management Company, LLC), one of the leading bond investment management companies (about \$ 1.844 billion in AuM, as end of June, 2019). Our choice fell on PIMCO's GIS Global Bond ESG Fund (EUR Hedged) because it is one of the first funds in the world to implement impact investing strategies within its investment portfolio, as well as one of the top 40 funds in Europe according to AuM.

The paper is organized as follows: paragraph 1 reviews the literature on the topic; paragraph 2 is for the empirical analysis; the last section concludes by commenting main results and suggesting for further research.

\section{Literature Review}

The application of ESG criteria to financial investments is becoming increasingly popular among operators; this trend has led to the development of a flourishing literature on related topics also in academic research. Integrating environmental, social and governance impacts into investment and financial decision making and 
especially focusing on the upside of ESG (positive) impact investing is a nascent field of research (Wendt, 2017). This review proposes a classification of the main contributions in recent years into two main strands: the first one explores investors' motivations to adopt ESG approach; the second one deals with the relationship between ESG criteria and investments' performance.

In the first strand, contributions identify two main groups of reasons that push investors towards esg approaches: personal attitudes; regulations-oriented behaviours towards sustainability issues. Brodback et al. (2018) provide survey evidence that there is a positive link between altruistic values and the relative importance of social responsibility and this effect is stronger when investors believe that they can make a positive social or environmental impact. Following the value-belief-norm theory (Stern et al., 1999), authors argue that egoistic values are negatively associated with the decision to invest responsibly. Brest et al. (2018), observing that an increasing number of socially motivated investors have goals beyond maximizing profits, deepen the topic of social value. They distinguish investors that seek investments aligned with their social values (value alignment) and investors that may also want their investments to make portfolio companies more social value (social value creation). The thrust of this essay is that while it is relatively easy to achieve value alignment, creating social value is much more difficult. Schramade (2017) refers to UN's Sustainable Development Goals (SDGs) as an engine for a path to value creation, both for society and shareholders. Bialkowski and Starks (2016), using a difference in difference approach, provide evidence that investor demand for socially responsible or sustainable and responsible funds results from investors' non-financial considerations. Moliterni (2018) addresses the topic considering esg criteria as an investment approach within sustainable investment, which can be traced back to seven main strategies: negative screening, norm-based screening, ESG integration, corporate engagement, best-in-class screening, impact investing, sustainability themed investing. Grabenwarter (2017) suggests a new form of "impact first" investing: rather than applying merely a negative screening filter that seeks to identify within a pool of random impact investment opportunities those that happen to meet a given risk/return profile, the focus needs to be on funding concrete impact solutions; once identified, impact solutions shall be translated into financial instruments which combine the risk/return profiles of a sufficiently large spectrum of investors in order to get a given impact solution funded. About ESG motivations, customer demand is certainly a key factor in the diffusion of these forms of investment, but another important aspect is the behavior of asset managers, with particular regard to their compliance with a kind of fiduciary duty towards investors: in this sense, we can refer to the study of Duuren at al. (2016), which on the basis of an international survey among fund managers find that many conventional managers integrate responsible investing in their investment process, using esg information for red flagging and to manage risk. Among the studies that deepen the topic of motivations to adopt ESG approaches in compliance with regulations, we can cite Wilson (2016) and Grabenwarter (2017), that consider the Sustainable Development Goals as business opportunities. Finally, other empirical evidence shows that investors incorporate religious and political values as well as social norms in their investment decisions (Hong \& Kostovetsky, 2012).

In the other strand, Landier and Nair (2009) had a first approach to the topic, building a so-called responsible portfolio, starting from the S\&P500 and therefore eliminating, year by year, companies that lacked sustainability, based on the KLD Analytics scores. They demonstated that it is possible to include esg criteria in portfolio choices without affecting financial returns. Weber et al. (2014) compare the aggregate performance of some SRI funds with the MSCI World Index and highlight that, on average, the SRI funds performed better than the index, but relying only on sustainability scores in the investment process does not lead to a positive financial return, therefore financial and esg analysis must be integrated. Verheyden et al. (2016) tested the effects of using different esg filters on an investable universe that serve sas the starting point for a fund manager, attempting to determine the extent to which esg data can add value to any investment approach. Their finding is that the incorporation of esg information contributes to better decision-making in every investment approach, with an unequivocally positive impact on risk-adjusted returns, using a $10 \%$ best-in-class screening approach. Soler-Domínguez and Matallín-Sáez (2016) assess the performance of the VICEX Fund, which is morally controversial due to its higher return premium on investments in well-established vice companies, representing an opposite extreme for socially responsible mutual funds Their findings suggest that the VICEX Fund underperforms during periods of economic distress, while it outperforms the market during expansion periods. Borgers et al. (2015) suggest that fund managers do not tilt heavily towards controversial stocks because of social considerations and practical constraints. About ESG ratings and Performance, we can also cite the following studies: Capelle-Blancard and Monjon (2014), Halbritter and Dorfleitner (2015), Brière and Szafarz (2017), Durán-Santomil et al. (2019), Galagedera (2019). 


\section{Empirical Analysis}

Considering the exploratory nature of our study, we adopted a qualitative approach using a case study on the GIS Global Bond ESG Fund (EUR Hedged) managed by PIMCO. The analysis is on two levels: 1) Characteristics of the GIS Global Bond ESG Fund (EUR Hedged); 2) Benchmarking analysis, through comparison between GIS Global Bond ESG Fund and Bloomberg Barclays Global Aggregate Index (benchmark). The theoretical foundation of the study can be traced back to the paper by Desclée et al. (2016), who studied the impact of the integration of esg criteria on a bond portfolio. The research question deals with the relationship between esg approaches and performance of investments.

\section{1) Characteristics of the GIS Global Bond ESG Fund (EUR Hedged)}

The Global Bond ESG Fund is characterized by a diversified portfolio of actively managed investments, consisting of a basket of worldwide fixed income securities, mainly investment grade bonds (generally not less than BBB rated), selected through an ESG screening process developed by PIMCO. The investment objective of the fund is to maximize total return, compatibly with capital protection and prudent investment management. This fund allows investors to benefit from a potential return similar to other 'core' bond strategies and, at the same time, have a positive social impact. The broad diversification of the fund can offer potential to generate outperformance compared to the benchmark, giving preference to issuers with the best ESG practices and those intent on optimizing them. Benchmark main reference is Bloomberg Barclays Global Aggregate (Euro Hedged) Index; the management start date is February 9,2017; reference currency is USD (US dollar); Equity: $\$ 677.5$ million (as end of June, 2019). The ESG Global Bond (EUR Hedged) is composed exclusively of fixed-income securities $(100 \%$ bond) and, in particular, both from corporate bonds $(48.66 \%)$ and government bonds $(51.34 \%)$ with a high credit rating (over $95 \%$ of the bonds have a rating equal to or greater than BBB).

About sectors, the main part is that one of semi-governmental instruments, securitized investments and investment grade credit (overall, about $90 \%$ of the total), while the municipal bond market, the high yield credit segment and emerging foreign currency debt represent only a small portion of the investment portfolio (around 7\% of the total). Portfolio consists of over 550 securities bonds, even if the weight of the first 10 items accounts as low as $80 \%$, indicating a strong concentration (such as in US Treasuries). This situation is probably due to a very difficult macroeconomic context, with particularly compressed global rates and, at the same time, a very high volatility due to different geo-political factors which significantly reduce profitable alternatives; moreover, the presence of an ESG screening, further reduces the list of fixed income securities capable of being included in the investment portfolio.

From a responsible investing perspective, it is interesting to note that over $10 \%$ of the fund is invested in Green bonds, worldwide issued, ie fixed income securities whose issue is linked to projects with a positive impact on the environment, such as, for example, efficiency energy, clean energy production and sustainable land use. With regard to the sectoral breakdown (Figure no. 1), the fund invests in green bonds linked both to governmental and project initiatives of Supranational Agencies, and to projects by firms belonging to many different sectors, such as banking, utilities, automotive, real estate or industrial services. As for the geographical distribution, green bonds are attributable for approximately one third to North America (17\% U.S.A. and 16\% Canada), over $20 \%$ to Europe and, finally, the remaining half is almost equally divided between Japan (17\%), supranational institutions $(12 \%)$ and the rest of the world (16\%).

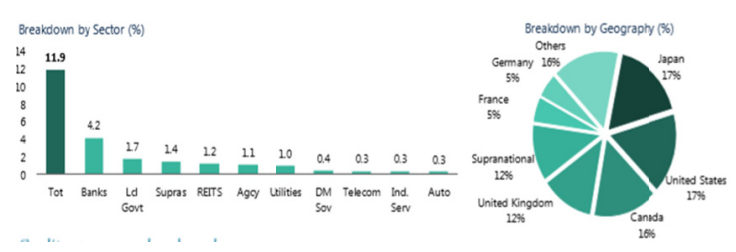

Figure 1. Green bonds exposure

Source: Pimco, 2019.

The selection of fixed-income securities takes place through a very rigorous approach, in four steps: 1) analysis of the main market trends (eg. environment, demography, technology);2) analysis of main trends in the bond market (eg duration of the securities, yield curve, volatility, interest rates, credit trends); 3) identification of the 
fund's objectives (in terms of duration, credit quality, geographical composition, etc.); 4) construction of the investment portfolio (monitoring liquidity, credit risk and fundamentals). In addition to all these factors, PIMCO adopts an internally developed screening process, which is based on three key elements aimed at influence positive changes, that is the so-called " 3 E screening" process: Exclusions, Evaluation, Engagement.

The first E is for "Exclusions" and it means that fixed income securities attributable to issuers deemed to be profoundly misaligned with the principles of social and environmental sustainability are excluded. Specifically, PIMCO adopts a double exclusion filter, the first one is "core", the second one is "dynamic". With regard to corporate bonds, the main core exclusions concern those issuing companies which belong to sectors that are particularly polluting and harmful to the environment, with a poor ethical profile, such as the sector of the production of controversial weapons (eg cluster bombs and mines), tobacco, pornography and the production and/or distribution of carbon. In particular, PIMCO tends to exclude those issuers whose revenues derive more than $10 \%$ from these businesses. As for government bonds, instead, the main core exclusions concern those states or supranational entities that have been seriously stained violations relating to the Global Principles of the United Nations, human rights or international labor conventions, that have been sanctioned by the UN Security Council, or that are characterized by low transparency and high corruption rates. To this first 'static' exclusion filter, PIMCO adds a dynamic list of issuers that, regardless of the sector, it considers misaligned with ESG principles. In particular, with regard to corporate securities, the fund tends to exclude those companies that adopt unacceptable working practices, which violate human rights and/or have a poor management. As for government bonds, instead, the fund excludes government bonds of countries with poor environmental practices.

The second E is for "Evaluation" and it means that PIMCO, in addition to excluding the worst issuers in ESG terms, takes into account those issuers that are distinguished by the use of robust social and environmental practices and present important margins for ESG improvement. Moreover, PIMCO selects securities through its own internally created system for assigning an ESG score, for each different type of credit obligation. As regards to corporate credit, PIMCO's ESG scoring system takes into account two factors: a) the validity of the ESG practices integrated in the business processes of an issuer, compared to its competitors in the same sector (factors E, S and G are analyzed separately and have relative weights, depending on the type of industry; for example, the environmental factor has the most important weight for those companies that operate in the extractive sectors, the social factor has the greatest weight in the pharmaceutical sector, while governance is the most relevant factor for financial companies); b) the trend of such ESG practices: PIMCO constantly monitors the progress of such ESG practices over time, to check if they are following an improving or a deteriorating trajectory. It is precisely from the combination of these two factors that the overall score emerges, which, together with the evaluation of the fundamentals of the asset, will make up the final judgment. Regarding government credit, PIMCO's ESG scoring system takes into account multiple factors attributable to 4 macro-areas: Environment, Social, Governance and International Sanctions. Each of these macro-areas has its own weight and determines the final score attributed to government and supranational bonds. The weight of the environmental factor has increased considerably in the last period, and its analysis has been made more detailed and precise through to the introduction of the following elements: a) risk measures related to the climatic transition (eg share of fossil fuels, share of renewable energy and $\mathrm{C} 02$ emissions); b) climate-related physical risk measures: includes the Notre Dame Global Adaptation Initiative Country Index, which measures the impact on the cost of capital for the governments of most countries vulnerable; c) health and environmental indexes (eg exposure to air pollution); d) indicators that evaluate the natural resources (eg: the Ocean Health Index, which measures the decline of biodiversity, overfishing or the deterioration of ocean health).

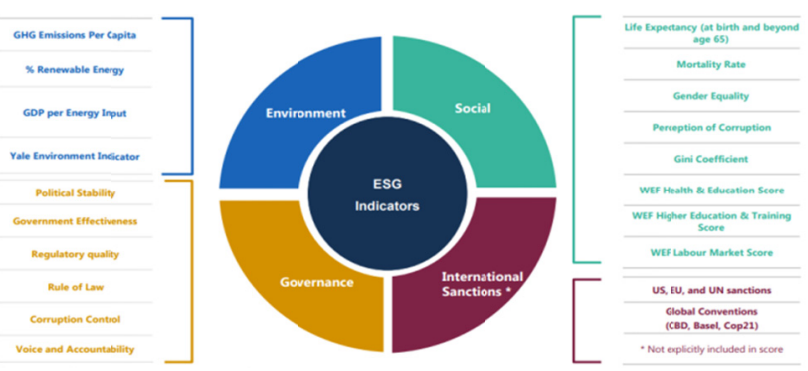

Figure 2. Esg indicators 
For the mortgage bond market, even in this case PIMCO has proceeded to build an internal rating system, which distinguishes between agency mortgages-backed securities (MBS) and non-agency residential mortgages (non-agency MBS) and provides a score from 1 (weakest) to 5 (best). Specifically, the manager of the GIS Global Bond ESG fund seeks to pursue the following 4 objectives in order to generate a positive impact: a) Support homeownership: PIMCO seeks to favor mortgages for the purchase of houses for residential purposes (especially if first home and / or in uninhabited neighborhoods); b) Increase access for underserved communities: PIMCO seeks to privilege mortgages for low-income borrowers, so as to generate a social benefit; c) Promote responsible lending: PIMCO seeks to protect mortgage borrowers, by investing in debt securities related to loans granted only to those able to sustain a reasonable plan of return, that is paying close attention to the debt / income ratio of the borrower; $\mathrm{d}$ ) discourage predatory lending and servicing: PIMCO exclludes from the portfolio of the fund the debt securities related to loans granted through harmful practices against borrowers. Figure $\mathrm{X}$ shows that the mortgages investments with a high ESG score, in which the GIS Global Bond ESG fund invests, go to meet mainly primary needs such as buying a first home, have a lower debt-to-income ratio and they are less substantial in terms of disbursed capital, thus generating a benefit for the most distressed population.

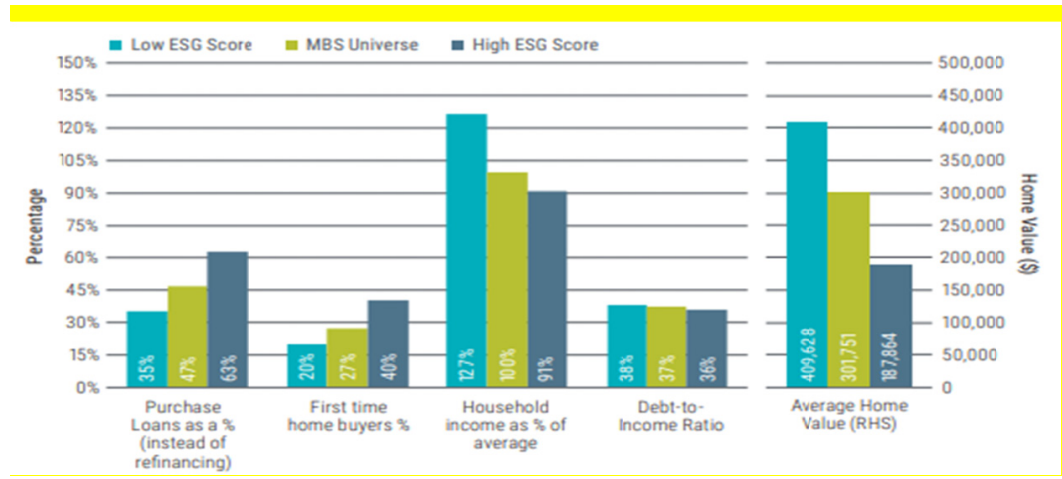

Figure 3. Mortgage investments across different esg profiles

Source: Pimco, Fannie Mae, Freddie Mac, Ginnie Mae.

Finally, as regards the U.S. market Municipal bond, PIMCO, with the support of independent analysts, has set up an internal rating system that takes into account multiple qualitative and quantitative factors attributable to the three macro-areas of reference of the ESG (Environmental, Social and Governance) and, more specifically, to the sustainable development goals of the United Nations (SDGs). Each municipal bond is valued on the basis of each factor and of each macro-area; the scores of each macro-area are, then, weighted by the relevance within the reference sector.

The last constituent element that drives PIMCO to select an investment is "Engagement", that is the constructive and collaborative commitment that issuers take in order to improve their ESG practices over time, generating a positive impact on the environment and society. PIMCO analyzes constantly the progress and commitment of each issuer thanks to an ad hoc internally developed database, that is COMET (Company Engagement Tracking), on which the profiles of each financed company are loaded; over time, PIMCO's global analysts analyze risks and performance of the different strategies adopted by the companies with respect to those ones of their competitors, evaluate the possible progress or deterioration with respect to the ESG objectives set at the beginning, and discuss with management if there are changes to be made. In this way, the portfolio will overweight those issuers that demonstrate a clear willingness to move towards best practices related to ESG, consistent in meeting the UN's sustainable development goals (SDGs).

Figure no. 4 shows that the fund has had a good performance, starting from its launch in 2017, generating an average annual return for the investor of approximately $1 \%$, net of management costs and exchange rate risk hedging. In particular, after a good start in $2017(+1.5 \%)$, the fund performance declined in $2018(-3.26 \%)$; this result must, however, be interpreted in relation to a particularly adverse market context, therefore not attributable to the particular characteristics of the fund. In 2019, however, despite the numerous geopolitical risks still strong, there has been a significant rally of the markets and all the performances of the main asset classes have positioned themselves in positive territory; the GIS Global Bond ESG (EUR Hedged) fully recovered all the loss 
suffered in 2018 ( $+4.69 \%$ compared to the previous year). While yields may not seem overwhelming at first glance, in a global flat rate environment performances (net of costs) are very good, especially if compared to the risks borne by the investor. Figure 5 summarizes main data about risk profile of the fund.

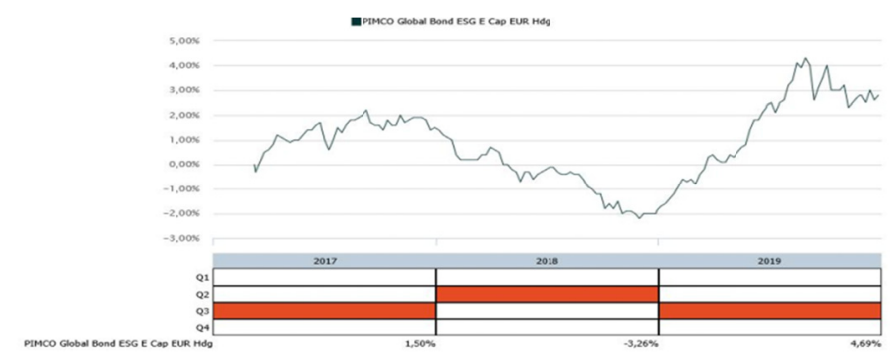

Figure 4. GIS Global Bond ESG, performance

Source: Fideuram Bank.

Table 1. GIS Global Bond ESG, risk profile

\begin{tabular}{ll}
\hline Index & value \\
\hline VaR $1 \mathrm{~d} 95 \%$ & $0.22 \%$ \\
VaR $3 \mathrm{~m} 95 \%$ & $1.73 \%$ \\
Volatility $6 \mathrm{~m}$ & $3.02 \%$ \\
Volatility $1 \mathrm{y}$ & $2.48 \%$ \\
Max drawdown 6m, 1y & $(2.11 \%)$ \\
Recovery period, 6m & $13 \mathrm{dd}$ \\
Recovery period, 1y & $52 \mathrm{dd}$ \\
Sharpe index & $\mathbf{1 . 7 8}$ \\
\hline
\end{tabular}

Source: Fideuram Bank.

Data show a very solid fund, in particular the Sharpe index is very high and the recovery times of the losses are very short.

2) Comparison between GIS Global Bond ESG Fund and Bloomberg Barclays Global Aggregate Index (benchmark)

The Bloomberg Barclays Global Aggregate Index (Euro Hedged) is a benchmark that offers a general indication on the performance of global bond markets. Specifically, it is a multi-currency index of fixed income investment grade securities and includes treasury, government securities, corporate and securitized securities relating to both developed and emerging countries. The main components of the benchmark are the following four regional indices, i.e.: the U.S. Aggregate index, the Pan-European Aggregate index, the Asian-Pacific Aggregate index, the Canadian Aggregate index. Table 2 shows the asset allocation of the fund and of the benchmark.

Table 2. Asset allocation

\begin{tabular}{lcc}
\hline Asset class & Asset allocation of fund & Asset allocation of bienchmark \\
\hline Semi-governmental & 43.40 & 51.40 \\
Inflation indexed & 5.20 & 0.00 \\
Supranational entities & 7.50 & 3.90 \\
Securitized & 31.80 & 12.50 \\
Covered bond and Pfandbriefe & 9.30 & 2.70 \\
Investment grade credit & 21.60 & 17.90 \\
High Yield Credit & 1.80 & 0.00 \\
Municipal & 3.40 & 5.20 \\
Emerging debt in foreign currency & 1.40 & 3.20 \\
Emerging debt in local currency & $\mathbf{( 9 . 7 0 )}$ & 3.30 \\
Others - short term (duration) & $\mathbf{( 1 5 . 6 0 )}$ & $\mathbf{0 . 0 0}$ \\
\hline
\end{tabular}

Source: Fideuram Bank. 
The fund underweights some sectors, while assumes higher exposures in other sectors compared to the benchmark: specifically, the fund significantly underweights the sector of semi-governmental instruments and, in particular, that one of emerging debt in local currency and other short-term instruments, where even it prefers to hold short positions. Conversely, the main overweighted sectors are inflation-linked debt, covered bonds and the securitized segment with a particular emphasis on the ESG profile.

Figure 5 shows the credi risk profile of investments. The GIS Global Bond ESG fund prefers to invest in issuers with an average rating higher than the benchmark; this result can be interpreted considering the highly selective ESG screening of the fund.

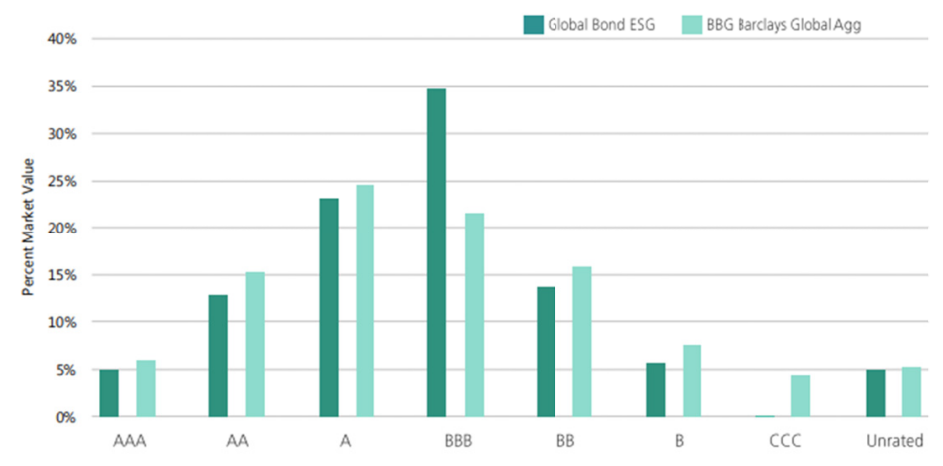

Figure 5. MSCI ESG ratings of corporate issuers

Source: MSCI.

Table 3 shows main data about performances and risk of the fund and benchmark.

Table 3. Performances

\begin{tabular}{lll}
\hline & PIMCO Global Bond ESG & $\begin{array}{l}\text { Bloomberg Barclays Global Aggregate } \\
\text { Index }\end{array}$ \\
\hline Gross performance 2018 & $(1.84 \%)$ & $(1.04 \%)$ \\
Gross performance 2019 & $6.11 \%$ & $5.58 \%$ \\
Average performance & $2.14 \%$ & $2.27 \%$ \\
Duration & $6,8 y y$ & $7,12 y y$ \\
Volatility & $2.48 \%$ & $4.72 \%$ \\
Max Drawdown & $2.11 \%$ & $2.25 \%$ \\
Sharpe index & $\mathbf{1 . 7 8 \%}$ & $\mathbf{1 . 1 8 \%}$ \\
\hline
\end{tabular}

Source: Fideuram Bank.

To "neutralize" the PIMCO management costs, in order to homogenize the data with the benchmark, we calculated the gross performances by adding the relative management costs to the net performances which, in the specific case of the Pimco Global Bond ESG, are around at $1.42 \%$, while in the case of the benchmark they are equal to 0 . Performances are quite similar, while in terms of riskiness the ESG fund has a more contained profile.

By investing in Pimco Global Bond ESG, investors are also able to know the impact generated for every million US dollars invested, in terms of: decent work, climate stability, healthy ecosystems, resource security, basic needs and wellbeing. A particular metric is used for each of these themes (Figure 6). 


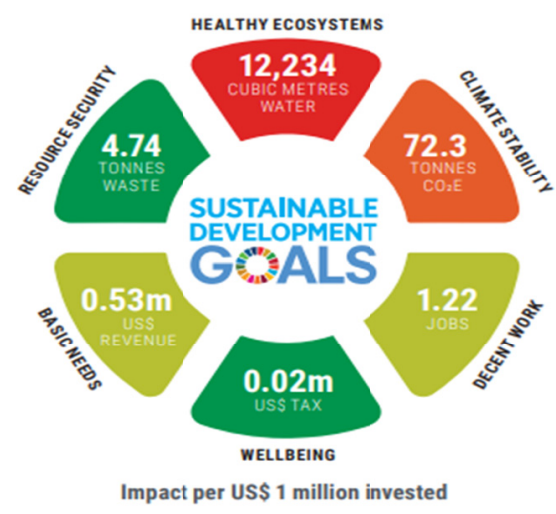

Figure 6. GIS Global Bond ESG, Sustainability results and metrics

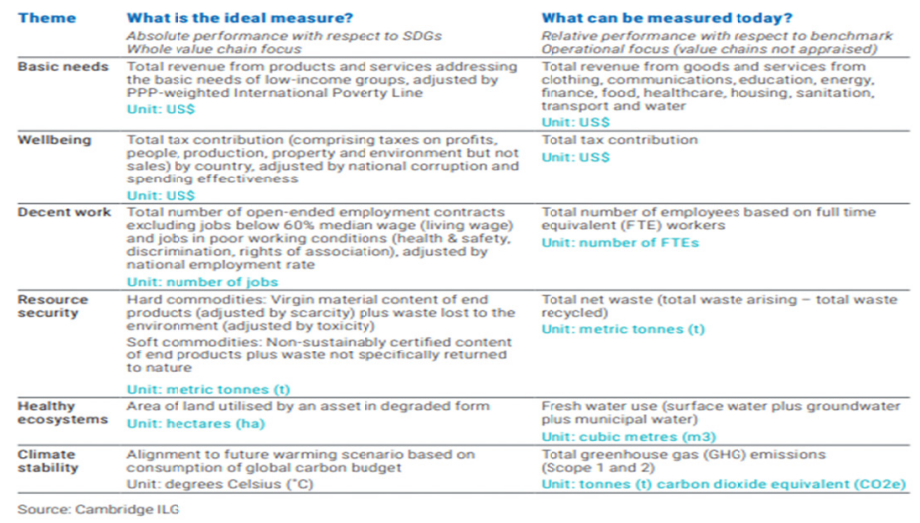

Specifically, we have analysed climate stability in more detail, as over the last period PIMCO's ESG efforts have focused heavily on building internal tools to assess climate change risks for fixed income investments. Increasing evidence shows that the energy transition and the rising global temperature have a significant impact on economic risks and credit risks. In particular, the investment implications of climate change, both in the short and long term, arise mainly from two factors: transition risks and physical risks- Transition risks include business risks for energy transition, such as stricter laws on carbon dioxide emissions, while physical risks include how climate change affects the natural resources on which the issuer depends. Given its growing importance also for the bond sector, in 2019 Pimco decided to integrate climate change into its ESG screening, to assess and monitor the alignment of the companies in which it invests and, consequently, its portfolios, with the UN Sustainable Development Goals and the Paris Agreement. One of the most important factor considered by PIMCO to integrate climate change into its selection processes is the intensity of carbon dioxide emissions by bond issuers. The impact of emissions is calculated by PIMCO through the use of production-based metrics (emissions per barrel, similar to oil and gas companies), which takes into account both direct and indirect emissions due, for example to electricity purchase, heating and cooling. The calculation is made by comparing the sum of the tons of carbon dioxide emitted for each business purpose to the respective company revenues. Companies in which the PIMCO Global Bond ESG Fund invests emit more than five times less carbon dioxide into the atmosphere than the issuers in the Barclays Global Aggregare Index, both in absolute and intensity terms.

\section{Discussion and Conclusions}

The global political framework seems to be increasingly converging towards a sustainable development. In line with the UN Sustainable Development Goals, the Paris Climate Change Agreements, the Principles of Responsible Banking, the inauguration speech of Ursula Von Der Leyen, the new President of the European Commission, presented a strong incentive programme to make Europe the first climate-free continent by the end of 2050. The financial system can make a significant contribution to this sustainable conversion: the intensity of 
the result will depend on the commitment to seek a fair balance between financial and social performance.

The intent of our analysis was to assess whether the use of ESG screening such as the one adopted by PIMCO for bond selection and the implementation of impact investing practices will affect investor performance. To date, the use of an esg filter seems to have a deterrent effect on investment volatility and seems to represent a competitive advantage in a long-term perspective. In the case of PIMCO Global Bond ESG, screening allows the fund to significantly reduce direct and indirect risks that can adversely affect the performance of issuing companies and, consequently, on the fund's portfolio, such as legal costs for social and environmental processes, expenses for business conversions, reputational damage, strikes and accidents at work, etc.

We proposed the analysis of this case for the relevance of the asset managed by Pimco, the company's esg commitment, the complex screening process developed by the same company. The research contributes to studies investigating the relationships between esg approaches and performance and risks of investments. Further investigations may expand the analysis by referring the study of the phenomenon to a wider time horizon.

\section{References}

Bialkowski, J., \& Starks, L. T. (2016). SRI Funds: Investor Demand, Exogenous Shocks and ESG Profiles. San Francisco, CA, USA.

Brest, P. A. Gilson, R. J., \& Wolfson, M. A. (2018). How Investors Can (and Can't) Create Social Value. European Corporate Governance Institute (ECGI) - Law Working Paper No. 394/2018; Stanford University Graduate School of Business Research Paper No. 18-23.

Brière, M., \& Szafarz, A. (2017). Factor Investing: Risk Premia vs. Diversification Benefits. Paris December 2016 Finance Meeting EUROFIDAI - AFFI.

Brodback, D., Guenster, N., \& Mezger, D. (2018). Altruism and Egoism in Investment Decisions (June 4, 2018). http://dx.doi.org/10.2139/ssrn.2978660

Capelle-Blancard, G., \& Monjon, S. (2014). The Performance of Socially Responsible Funds: Does the Screening Process Matter? European Financial Management, 20(3), 494-520. https://doi.org/10.1111/j.1468-036X.2012.00643.x

Durán-Santomil, P., Otero-González, L., Correia-Domingues, R. H., \& Reboredo, J. C. (2019). Does Sustainability Score Impact Mutual Fund Performance? Sustainability, 11, 2972. https://doi.org/10.3390/su11102972

Duuren, V. E., Plantinga, A., \& Scholtens, B. (2016). ESG Integration and the Investment Management Process: Fundamental Investing Reinvented. Journal of Business Ethics, 138(3), 525-533. https://doi.org/10.1007/s10551-015-2610-8

Galagedera, D. (2019). Modelling social responsibility in mutual fund performance appraisal: A two-stage data envelopment analysis model with non-discretionary first stage output. European Journal of Operational Research. https://doi.org/10.1016/j.ejor.2018.08.011

Grabenwarter, U. (2017). Solution-Driven Finance: The New Way of 'Impact First' Why Serving Organic Lobster on Titanic Won't Do the Trick (June 22, 2017). http://dx.doi.org/10.2139/ssrn.2990907

Halbritter, G., \& Dorfleitner, G. (2015). The wages of social responsibility - where are they? A critical review of ESG investing. Review of Financial Economics, 26, 25-35. https://doi.org/10.1016/j.rfe.2015.03.004-

Hong, H. G., \& Kostovetsky, L. (2012). Red and Blue Investing: Values and Finance. Simon School Working Paper No. FR 09-06; EFA 2009 Bergen Meetings Paper. http://dx.doi.org/10.2139/ssrn.1214382

Landier, A., \& Nair, V.B. (2009). Investing for Change: Profit from Responsible Investment. Oxford University Press, Incorporated.

Moliterni, F. (2018). Sustainable Investing and Green Finance: Boosting Markets by Solving Ambiguities. FEEM Policy Brief No. 1.2018.

Schramade, W. (2017). Investing in the UN Sustainable Development Goals (May 16, 2017). http://dx.doi.org/10.2139/ssrn.2968791

Soler-Domínguez, A., \& Matallín-Sáez, J. C. (2016). Socially (ir)responsible investing? The performance of the VICEX Fund from a business cycle perspective. Finance Research Letters, 16, 190-195.

Stern, P. C, Dietz, T., Abel, T., Guagnano, G. A., \& Kalof1, L. (1999). A value-belief-norm theory of support for social movements: The case of environmentalism. Research in Human Ecology, 6(2), 81-97. 
Tyler, J. E. (2018). Structuring for Action and Longevity in the Green Economy: Being Intentional About Committing to Social/Green Purposes, Connecting Effort and Impact, and Addressing Harm and Accountability. University of Missouri-Kansas City Law Review, 86(4).

Verheyden, T., Eccles, R. G., Feiner, A. (2016). ESG for All? The Impact of ESG Screening on Return, Risk, and Diversification. Journal of Applied Corporate Finance, 28(2), 47-55.

Weber, O. (2014). The financial sector's impact on sustainable development. Journal of Sustainable Finance \& Investment, 4(1), 1-8. https://doi.org/10.1080/20430795.2014.887345

Wendt, K. (2017). Social Stock Exchanges - Democratization of Capital Investing for Impact (August 18, 2017). 30th Australasian Finance and Banking Conference 2017. http://dx.doi.org/10.2139/ssrn.3021739

Wilson, K. E. (2016). Investing for Social Impact in Developing Countries. Development Co-operation Report 2016: The Sustainable Development Goals as Business Opportunities. http://dx.doi.org/10.1787/dcr-2016-en

\section{Copyrights}

Copyright for this article is retained by the author(s), with first publication rights granted to the journal.

This is an open-access article distributed under the terms and conditions of the Creative Commons Attribution license (http://creativecommons.org/licenses/by/4.0/). 